\title{
Handshaking Promotes Cooperative Dealmaking
}

\section{Citation}

Schroeder, Juliana, Jane Risen, Francesca Gino, and Michael I. Norton. "Handshaking Promotes Cooperative Dealmaking." Harvard Business School Working Paper, No. 14-117, May 2014.

\section{Permanent link}

http://nrs.harvard.edu/urn-3:HUL.InstRepos:13479245

\section{Terms of Use}

This article was downloaded from Harvard University's DASH repository, and is made available under the terms and conditions applicable to Open Access Policy Articles, as set forth at http:// nrs.harvard.edu/urn-3:HUL.InstRepos:dash.current.terms-of-use\#OAP

\section{Share Your Story}

The Harvard community has made this article openly available.

Please share how this access benefits you. Submit a story.

Accessibility 


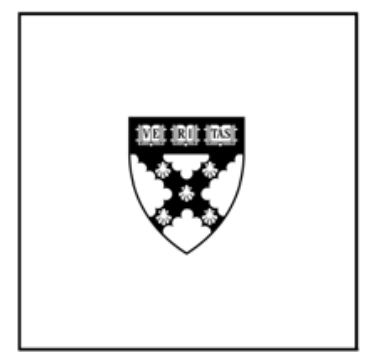

\section{Handshaking Promotes Cooperative Dealmaking}

Juliana Schroeder

Jane Risen

Francesca Gino

Michael I. Norton

\section{Working Paper}

14-117

May 30, 2014 
RUNNING HEAD: Handshaking

\title{
Handshaking Promotes Cooperative Dealmaking
}

\author{
Juliana Schroeder \\ Jane Risen \\ University of Chicago \\ Francesca Gino \\ Michael I. Norton \\ Harvard University
}

Word Count: 7,073 


\begin{abstract}
Humans use subtle sources of information - like nonverbal behavior - to determine whether to act cooperatively or antagonistically when they negotiate. Handshakes are particularly consequential nonverbal gestures in negotiations because people feel comfortable initiating negotiations with them and believe they signal cooperation (Study 1). We show that handshakes increase cooperative behaviors, affecting outcomes for integrative and distributive negotiations. In two studies with MBA students, pairs who shook hands before integrative negotiations obtained higher joint outcomes (Studies $2 \mathrm{a}$ and $2 \mathrm{~b}$ ). Pairs randomly assigned to shake hands were more likely to openly reveal their preferences on trade-off issues, which improved joint outcomes (Study 3). In a fourth study using a distributive negotiation, pairs of executives assigned to shake hands were less likely to lie about their preferences and crafted agreements that split the bargaining zone more equally. Together, these studies show that handshaking promotes the adoption of cooperative strategies and influences negotiation outcomes.
\end{abstract}

Word Count: 150

Keywords: Handshake; Negotiation; Cooperation; Integrative; Distributive 


\section{Handshaking Promotes Cooperative Dealmaking}

At the beginning of a contentious and high stakes negotiation regarding Iran's nuclear program, American President Barack Obama and Iranian President Hassan Rouhani scheduled a meeting. The meeting took months to arrange but it had only one item on the agenda: a handshake. This simple handshake was meant to facilitate future negotiations. When Rouhani refused to meet at the last moment, American pundits referred to the incident as the "historic non-handshake," suggesting that negotiations would be irreparably damaged by the "non-gesture" (Landler, 2013, p. A9).

How could a simple handshake have such extreme consequences for the negotiation? We suggest that handshakes before negotiations — or the lack thereof-serve as subtle but critical indicators of negotiators' social motives. In particular, handshakes signal willingness to act cooperatively during negotiations. We propose and show that handshakes increase cooperative behaviors at the bargaining table and, as a result, influence outcomes in both integrative and distributive negotiations.

\section{Handshakes as a Signal of Negotiators' Cooperative Motives}

Unlike many other types of social interactions in which people seem willing to cooperate even with strangers (Fehr \& Fischbacher, 2003; Henrich, 2012), negotiations are adversarial contexts that can instead induce the desire to compete (Pruitt, 1981). Negotiators' social motives are critical predictors of their decisions to cooperate or to compete (Deutsch, 1949; Pruitt \& Lewis, 1975; Pruitt \& Rubin, 1986). These social motives, particularly in negotiations between people who do not already know each other, develop in part from immediate evaluations of the counterpart. 
People are adept at drawing impressions of others in a short amount of time. Even in just $100 \mathrm{~ms}$, below the level of consciousness, people form reliable judgments about how attractive, likable, trustworthy, competent, and aggressive a face is (Willis \& Todorov, 2006) and these immediate inferences of competence can predict consequential outcomes such as who will win a political election (Todorov, Mandisodza, Goren, \& Hall, 2005). With more time to observe someone's expressive behaviors, including how they move and gesture, people derive a wealth of social information that is surprisingly accurate. For instance, strangers' ratings of five minute videotaped clips of targets correlate with targets' own self-ratings (Funder \& Colvin, 1988). In a meta-analysis of 44 studies, the accuracy of people's impressions were no different based on observations under half a minute in length compared to those based on longer observations of five minutes, suggesting that only about 30 seconds of information are necessary to form a relatively accurate impression of someone (Ambady \& Rosenthal, 1992). Further, whereas people may rely on verbal information to judge others during longer interactions (Ames, Fiske, \& Todorov, 2011; Hall \& Schmid-Mast, 2007), when forming initial impressions people seem to rely more on nonverbal information (Argyle, 1988; DePaulo, 1992; De Gelder et al., 2010). For instance, ratings of 30 second silent clips of college teachers' nonverbal behaviors predict endof-semester student and principal evaluations (Ambady \& Rosenthal, 1993). This suggests that the nonverbal behavior someone displays within the first minute or less of a meeting can not only predict evaluations of that person but also future behavior toward the person.

According to the social meaning model (Burgoon, Buller, \& Woodall, 1989), nonverbal behaviors comprise a socially shared vocabulary analogous to verbal communications. For example, individuals form reliable impressions of a relationship based on the nonverbal behavior of interactants in a photograph. Compared to observing common nonverbal behaviors such as 
proximity, eye contact, body lean, and smiling, observing people touching, in particular, leads to the strongest beliefs that the relationship involves intimacy, immediacy, emotionality, and dominance (Burgoon, Buller, Hale, \& deTurck, 1984). Interpersonal touch generally plays a central role in social interaction, predicting outcomes ranging from tipping at restaurants (Stephen \& Zweigenhaft, 1986) to maintaining loving relationships (Gallace \& Spence, 2010; Harlow, 1958). But different types of touch convey different signals. For instance, holding hands conveys greater affection than shaking hands, but shaking hands conveys greater formality (Burgoon, 1991).

In Western cultures, a handshake is a common greeting used in both approaching and closing salutations (Astrom, 1994). In contrast to other types of nonverbal gestures-even those that involve touch, like holding hands or hugging, which may convey greater affection but are also less commonly used as a greeting between strangers - we predict that people will feel most comfortable initiating a handshake at the beginning of a negotiation (Hypothesis 1).

Handshakes not only send a friendly greeting but can also indicate a sociable personality (Chaplin, Phillips, Brown, Clanton, \& Stein, 2000). In one study, a firm handshake was positively related to extraversion and emotional expressiveness and negatively related to shyness and neuroticism (Chaplin et al., 2000). Individuals who follow common prescriptions for shaking hands, such as having a firm grip and looking the other person in the eye, receive higher ratings of employment suitability in job interviews (Stewart, Dustin, Barrick, \& Darnold, 2008). Witnessing individuals shaking hands in a business setting leads observers to more positively evaluate the relationship and show increased activation in their nucleus accumbens, suggesting people feel rewarded for merely watching others shake hands (Dulcos, Sung, Argo, Flor-Henry, \& Dulcos, 2012). These studies indicate that handshakes convey a message of warmth and 
friendliness. In the context of a negotiation, this message could further suggest a willingness to cooperate. In fact, Neale and Northcraft (1991) suggested that negotiators who have a friendlier and less contentious style of interaction encourage a higher level of trust, cooperation, and information exchange in their counterparty, and are thus more likely to reach integrative agreements. We predict that, of the relevant nonverbal behaviors that people would feel comfortable doing at the start of a negotiation, people would believe a handshake is most likely to indicate cooperative motives (Hypothesis 2).

To consider not only whether but also how handshakes promote cooperation, we utilize two paradigmatic adversarial scenarios: integrative and distributive negotiations. In integrative negotiations, parties' interests are neither completely opposed nor completely compatible, allowing negotiators to mutually benefit by making efficient trades (Fisher \& Ury, 1981; Pruitt, 1981; Raiffa, 1982). Cooperative motives produce higher joint outcomes in integrative negotiations due to parties' increased willingness to openly reveal their priorities, facilitating mutually beneficial trades (De Dreu, Weingart, \& Kwon, 2000; Thompson, Mannix, \& Bazermann, 1988; Weingart, Bennett, \& Brett, 1993; Weingart, Hyder, \& Prietula, 1996). In social interactions and in negotiation more specifically, both seeking and providing information tends to be reciprocated, which encourages open information exchange (Thompson \& Hastie, 1990; Weingart, Bennett, \& Brett, 1993). Truthful information about the counterparty's preferences allows negotiators to maximize joint gains in integrative negotiations (Murnighan, Babcock, Thompson, \& Pillutla, 1999). In fact, misperceptions of the counterparty's interests are a primary cause of suboptimal negotiation outcomes (Thompson \& Hastie, 1990). We predict that, because handshakes convey and incite cooperative motives, they would manifest in the consequential cooperative behavior of open priority exchange in integrative negotiations 
(Hypothesis 3a). More open priority exchange between the interactants who shake hands should then result in higher joint outcomes (Hypothesis 3b).

In contrast, distributive or "zero-sum" negotiations - in which the parties' interests are completely opposed - are characterized by a different set of strategies such as appearing firm and even lying about one's interests (Pruitt \& Lewis, 1975). Whereas negotiators may show cooperative behaviors in integrative negotiations, they are more likely to show antagonistic behaviors in distributive negotiations. In such negotiations, having cooperative motives may reduce these antagonistic behaviors and encourage negotiators to more highly value fairness and joint welfare (Giebels, De Dreu, \& Van de Vliert, 2000; Kelley \& Thibaut, 1978; Van Lange, 1999). We predict that shaking hands prior to distributive negotiations would lead negotiators to engage in fewer antagonistic behaviors such as lying about their interests (Hypothesis 4a). Reduced lying should then result in more equitable outcomes for negotiators who shake hands (Hypothesis 4b).

\section{Overview of the Present Research}

We test these predictions in five studies. Study 1 examines whether handshakes are uniquely relevant for negotiations in contrast to other nonverbal gestures because people feel most comfortable initiating them at the start of a negotiation (Hypothesis 1). It also examines whether people have the intuitive belief that a handshake signals cooperation (Hypothesis 2). Studies $2 \mathrm{a}$ and $2 \mathrm{~b}$ consider the relationship between shaking hands and integrative negotiation outcomes. In these studies, MBA students choose to shake hands or not prior to negotiating and we measure the negotiation consequences of handshaking.

To causally test whether handshakes improve negotiation outcomes, and to test for our predicted mediators, we assign pairs to shake hands or not in Studies 3 and 4. Study 3 tests the 
effect of a handshake in an integrative negotiation that we videotaped in order to code for our predicted mediator of open priority exchange (Hypotheses 3a and 3b). Study 4 tests the effect of a handshake in a distributive negotiation in which we also measure lying behavior (Hypotheses $4 \mathrm{a}$ and $4 \mathrm{~b})$. Across these studies, we expect to find that handshakes are uniquely relevant nonverbal gestures in negotiations that signal cooperative motives, leading to improved and more equitable outcomes in integrative and distributive negotiations, respectively.

\section{Study 1: Nonverbals in Negotiations}

We asked an online sample of Americans to report which behaviors they would feel comfortable doing at the start of a negotiation, and then to select the one behavior that they believed would lead to the most cooperative negotiation. In order to compare beliefs about shaking hands to beliefs regarding as many other types of nonverbal behaviors as possible, we surveyed participants about a wide range of behaviors. We predicted that out of all these behaviors, people would feel most comfortable shaking hands with the counterparty and would also believe a handshake is most likely to produce a cooperative negotiation.

\section{Method}

Participants. Fifty Amazon Turk workers $\left(M_{\mathrm{age}}=31.28, S D=9.80,34\right.$ males) who were U.S. citizens completed a survey about negotiations in exchange for $\$ 0.30$ each.

Procedure. We told participants to "imagine you are about to have an important business negotiation with someone you have never met before. Which of the following gestures would you feel comfortable doing with the counterparty (i.e., the person you will negotiate with) before the negotiation?" Participants could check multiple gestures. The list included twelve gestures (randomly ordered) that we thought individuals might be willing to do before a negotiation and which might affect evaluations (both positive and negative) of the counterparty: four gestures 
that involved touch: shake hands with the counterparty, hold hands with the counterparty, touch the arm or shoulder of the counterparty, hug the counterparty; four gestures that conveyed a positive greeting: wave at the counterparty, make positive eye contact (e.g., an open gaze) with the counterparty, wink at the counterparty, bow or nod your head to the counterparty; and four gestures that conveyed a negative greeting: frown at the counterparty, look or turn away from the counterparty, cross arms in front of your chest, make negative eye contact (e.g., glare) at the counterparty. Next, we showed participants a list of the behaviors they had selected and asked them to choose the one gesture that they believed would "lead to the most cooperative (e.g., the most friendly and positive) negotiation experience."

\section{Results}

$100 \%$ of participants reported that they would be comfortable shaking hands with the counterparty at the start of a negotiation. $90 \%$ of participants also reported they would be comfortable making positive eye contact, $60 \%$ would bow or head nod to the counterparty, and $44 \%$ would wave. Less than one third of the participants selected the other eight options, showing that only a minority would feel comfortable doing these nonverbal behaviors at the start of a negotiation. Participants selected handshake more than every other option, even marginally more than positive eye contact, $\chi^{2}(1,50)=3.37, p=.07, \varphi=0.26$.

The majority of participants also chose handshake as the one behavior that would lead to the most cooperative negotiation experience ( 34 people), significantly more than the number who selected positive eye contact (13 people), $\chi^{2}(1,50)=12.97, p<.01, \varphi=0.51$. In contrast, just one person selected touching the counterparty's arm, one selected hugging, and one selected waving.

\section{Discussion}


Not only did all people surveyed feel comfortable shaking hands at the start of a negotiation, shaking hands was the gesture most frequently selected that people would feel comfortable doing compared to the other nonverbal gestures. Further, shaking hands was also most often selected as the one behavior that would lead to a cooperative negotiation. These results highlight why handshakes are uniquely relevant to producing cooperative motives in negotiations: first, because people are willing to engage in them before the negotiation and, second, because they signal cooperation.

\section{Study 2a: MBA Integrative Negotiations}

Before experimentally testing the effect of handshakes on negotiation outcomes, we first measured the relationship between handshakes and integrative negotiation outcomes in Studies $2 \mathrm{a}$ and $2 \mathrm{~b}$. Although randomly assigning pairs to shake hands is necessary to determine the causal effect of handshakes, such experiments suffer from a demand artifact: participants might infer that they are supposed to act cooperatively when an experimenter tells them to shake hands. A correlational design instead allows us to observe the relationship between handshakes and negotiation outcomes without any such experimental demand artifacts.

We expected that handshakes would correlate with higher joint outcomes in integrative negotiations. In Study 2a, MBA students in a negotiation class chose to shake hands or not before an integrative negotiation and subsequently reported their outcomes in a survey.

\section{Method}

Participants. One hundred six MBA student pairs ${ }^{1}$ who attended a negotiation course at a top business school in the Midwestern United States completed an integrative negotiation.

Procedure. Participants completed their negotiation in class with a randomly assigned partner. To increase our sample size and generalizability, we sampled across two classes. One

\footnotetext{
${ }^{1}$ We did not collect participants' demographic information.
} 
class completed the New Car negotiation (Nadler, Thompson, \& Morris, 1998; $n=37$ ); the other completed the New Recruit negotiation (Neale, 2006; $n=69$ ). After the negotiation, each pair completed a survey.

Materials. The New Car and New Recruit negotiations require pairs to negotiate the buying and selling of a car, and the job offer details for a new employee, respectively. Both negotiations have exactly the same structure: pairs negotiate eight issues with five outcome options for each issue. For instance, in the car negotiation, parties must determine a car price ranging from $\$ 50,000$ to $\$ 58,000$ in $\$ 2,000$ increments, a car color (black, red, blue, green, or yellow), and so on. Each party has a point schedule in their confidential information that explains their preferences. Of the eight issues, two are distributive (parties have opposite preferences of the same point magnitude), two are compatible (parties have the same preferences), and four are variable-sum (parties have opposing preferences but different point magnitudes). If negotiators integrate their interests by compromising across the variable-sum issues, they can divide more points than if they compromise on each of the variable-sum issues individually. Based on the pairs' decisions on the issues, each party achieves a number of points representing the extent to which they achieved their interests in the negotiation.

The survey asked pairs whether or not they shook hands with their partner before beginning the negotiation (Yes, No, or Do not remember), whether or not they knew their partner prior to the negotiation (Yes or No), and how much they enjoyed the negotiation $(1=$ Not at all; $7=A \operatorname{lot})$

\section{Results}

Because both negotiations have the same integrative structure but different possible point totals, we standardized the pairs' total scores for each of the two negotiations. Of the 106 pairs, 
three of these did not report their final score in the survey and are therefore dropped from analyses. Pairs who shook hands $(n=74)$ had a higher joint outcome $(M=0.13, S D=0.92)$ than pairs who did not shake $(n=29 ; M=-0.33, S D=1.11), t(101)=2.13, p=.04, d=0.45$. Negotiation type did not moderate the effect of shaking on point totals, $F(1,99)<1$.

There was no effect of shaking hands on how much pairs reported enjoying the negotiation, (handshake vs. no handshake: $M=5.93, S D=0.96$ vs. $M=5.62, S D=1.15), t(101$ ) $=1.41, p>.10$.

Whether or not pairs previously knew each other did not affect their likelihood of shaking, $\chi^{2}(1,103)<1$, marginally improved their joint score, $t(101)=1.66, p=.099, d=0.33$, and did not moderate the effect of shaking on point totals, $F(1,99)<1$.

Shaking hands predicted the joint score when controlling for knowing each other in a linear regression, $\beta=-0.21, p=.04$.

\section{Discussion}

These results suggest that negotiators who shake hands earn higher joint integrative outcomes. Because we asked about handshaking after the negotiation was complete, it is possible that pairs who achieved higher joint outcomes were simply more likely to remember shaking hands - regardless of whether they actually did. We therefore videotaped another group of MBA students negotiating in Study $2 \mathrm{~b}$.

\section{Study 2b: Videotaped MBA Integrative Negotiations}

In order to replicate the effects in Study $2 \mathrm{a}$ and to rule out memory bias as a possible explanation for the results, we videotaped a new sample of MBA students completing an integrative negotiation case that they had prepared at home.

\section{Method}


Participants. Thirty five pairs of MBA students (51 males) who attended an advanced negotiation course at a top business school in the Midwestern United States completed an integrative negotiation.

Procedure \& Materials. In the World Premier negotiation (Massey \& Nolan, 2010), participants negotiate the production of a play on five issues that involve a combination of distributive, compatible, and variable-sum point distributions. Two research assistants coded participants' videos on three criteria: first, whether or not the pairs shook hands at the start the negotiation, second, the total joint points that the pairs achieved, and third, whether or not the pairs shook hands at the end of the negotiation. Because participants were taught to negotiate using complete pre-calculated packages and therefore typically revealed their priorities only through full package offers instead of explicitly discussing their preferences for one issue at a time, we were unable to code for our predicted mediator of open priority exchange in the videos for this study.

\section{Results}

There was no disagreement between the research assistants on their coding $(r=1.0)$. Pairs who shook hands prior to the negotiation $(n=15)$ again garnered more joint points $(M=$ $1288.0, \mathrm{SD}=10.8)$ than pairs who did not shake hands $(n=20 ; M=1275.5, S D=21.4), t(33)=$ 2.07, $p=.047, d=0.74$, and were directionally more likely to shake hands upon the conclusion of the negotiation as well (handshake vs. no handshake: $M=80.0 \%, S D=41.4 \%$ vs. $M=55.0 \%$, $S D=51.0 \%), \chi^{2}(1,35)=2.38, p=.12$.

\section{Discussion}

Study $2 \mathrm{~b}$ replicates the result of Study $2 \mathrm{a}$, showing that pairs who shake hands earn higher joint negotiation outcomes. Of course, we cannot conclude that handshakes causally 
improve outcomes from these studies. It is possible, for instance, that people with more cooperative motives are just more likely to shake hands. In order to demonstrate the causal impact of shaking hands on improved outcomes, and to examine whether increased cooperative behavior - in the form of open exchange of negotiation priorities - drives the effect of handshakes on outcomes, we turn to a laboratory setting in Study 3.

\section{Study 3: Integrative Negotiations in the Lab}

We randomly assigned pairs of undergraduates to shake hands or not prior to completing a videotaped integrative negotiation with three issues. In this negotiation, the pairs had identical preferences on one issue and variable-sum preferences for the other two issues. By revealing how much they value one issue compared to the other issue, pairs can make optimal tradeoffs on the two issues, thereby maximizing their total points. To measure our predicted mediator of priority exchange, we asked two independent research assistants to code the videos for how openly the pairs discussed the two variable-sum issues.

\section{Method}

Participants. One hundred twenty undergraduate students $\left(M_{\text {age }}=20.9, S D=4.9,64\right.$ males) completed an integrative negotiation and received $\$ 3$.

Procedure. Participants negotiated the job offer details for a new employee. After confirming that participants were unacquainted, we randomly assigned one of them to the role of "Boss" and the other to the role of "Candidate" in the negotiation. The experimenter explained the instructions separately to each participant and gave them their role information. We informed participants that the person who received the best score in the study would earn an additional $\$ 30$.

We seated pairs at opposite ends of a large table during the negotiation. We randomly assigned half of the pairs to shake hands before sitting down. For these pairs, the experimenter 
led them toward the table, then paused and said: "It is customary for people to shake hands prior to starting a negotiation." The experimenter waited until the participants had shaken hands, and then seated them. Participants in the no handshake condition were seated immediately, giving them no opportunity to shake hands ("It is customary to sit across from your partner when starting a negotiation"). Therefore, pairs were never explicitly instructed to shake hands or not, minimizing experimental demand concerns. Pairs negotiated for no more than 10 minutes on video, then completed a survey in separate rooms.

Materials. In the Job Search negotiation (Fishbach, 2013), the Boss and Candidate must decide upon the salary, start date, and office location for the candidate. Both parties prefer the same location but have opposite preferences for salary and start date. Because the Candidate cares more (i.e., has higher point magnitude) about salary but the Boss cares more about start date, the solution that maximizes joint points is to allow the Candidate the highest salary and the Boss the earliest start date.

The survey measured feelings about the negotiation experience with seven questions. ${ }^{2}$ Most relevant to our hypothesis, two of these questions directly asked participants about how cooperatively they behaved in the negotiation $(r=0.52, p<.01)$ : What was your negotiation strategy? (included a description of possible strategies, $1=$ Very competitive; $7=$ Very cooperative); How open were you with your partner about your true underlying interests in the negotiation? $(1=$ Not at all open; $7=$ Very open $)$. Three of these questions asked about impressions toward the partner $(\alpha=0.77)$ : What was your overall impression of your partner? ( 1 =Very negative; 7 = Extremely positive $)$ How much did you like your partner? $(1=$ Did not like at all; $7=$ Extremely liked); How much did you enjoy the negotiation process with your partner?

\footnotetext{
${ }^{2}$ Unsurprisingly, since we designed the questions to measure different aspects of how negotiators felt about their partner and the negotiation, all seven items did not have high reliability together: $\alpha=0.62$.
} 
$(1=$ Did not enjoy at all; $7=$ Extremely enjoyed $)$. Finally, we also asked participants how they felt at the negotiation's start and interest in negotiating again: How did you feel at the start of the negotiation? $(1=$ Very uncomfortable; 7 =Very comfortable $)$; How much would you want to negotiate again with your partner? $(1=$ Not at all; $7=$ Extremely $)$.

Two research assistants who were blind to the hypothesis coded participants' videos on six pre-determined criteria: openness of priority exchange (our predicted mediator), concessions, lies, talking after negotiation, shaking hands after negotiation, and posture. We resolved discrepancies on any criteria using a third coder, also blind to hypothesis. Openness was coded: 0 $=$ no comparison of how much each party cared about the two issues; $1=$ boss expressed strong preference for start date or candidate expressed strong preference for salary; $2=$ boss expressed greater preference for start date than salary or candidate expressed greater preference for salary than start date. Openness was summed across the two parties. Concessions were defined as explicit offers that would bring the party fewer points than a prior offer. Lies were defined as offers made outside the stated boundaries in the case. Talking and shaking hands after reaching agreement were each dichotomous measures. ${ }^{3}$ Posture was coded: $1=$ leaned away from each other; 2 = no leaning; 3 = leaned toward each other.

\section{Results}

Negotiation Outcomes. Shown in Figure 1, we conducted a 2 (role: Boss vs. Candidate) within-pair x 2 (handshake: present vs. absent) between-pair ANOVA on the pairs' point outcomes. As predicted, pairs who shook hands achieved higher joint outcomes than pairs who did not shake hands, $F(1,58)=6.67, p=.01, \eta_{p}^{2}=0.10$. Bosses achieved more points than candidates, $F(1,58)=20.66, p<.01, \eta_{p}{ }^{2}=0.26$, but there was no interaction, $F(1,58)=0.29$.

\footnotetext{
${ }^{3}$ Although participants were instructed to get the experimenter after the negotiation was complete, twenty out of the sixty pairs stayed in the room and chatted after reaching an agreement-which we caught on video before the experimenter returned to turn off the video camera.
} 
Behavior During Negotiations. Descriptive statistics for video coding are shown in Table 1. As predicted, pairs who shook hands discussed their preferences more openly on the two variable-sum issues, our proposed mediator, $t(58)=3.64, p<.01, d=0.96$. Handshaking had additional positive effects: pairs who shook hands lied less, $t(58)=-2.28, p=.03, d=-0.60$, were more likely to talk after reaching agreement, $\chi^{2}(1,60)=4.04, p=.04, \varphi=0.18$, were more likely to shake hands after reaching agreement, $\chi^{2}(1,60)=7.10, p<.01, \varphi=0.24$, and were more likely to lean toward each other, $t(58)=4.58, p<.01, d=1.20$, but did not make more concessions, $t(58)<1$.

\section{Table 1}

Negotiation behaviors assessed in Study 3 by condition

\begin{tabular}{lcccccc}
\hline & & & Talked & Shook Hands \\
& Openness & Concessions & Lies & After Deal & After Deal & Posture \\
\hline Handshake & 2.23 & 3.61 & 0.48 & $45.2 \%$ & $58.1 \%$, & 2.68 \\
& $(1.63)$ & $(2.01)$ & $(0.68)$ & $(50.6 \%)$ & $(50.2 \%)$ & $(0.79)$ \\
No Handshake & 0.97 & 3.21 & 1.03 & $20.7 \%$ & $24.1 \%$, & 1.66 \\
& $(0.94)$ & $(2.42)$ & $(1.15)$ & $(41.2 \%)$ & $(43.5 \%)$ & $(0.94)$ \\
\hline & $p<.01$ & $p>.10$ & $p=.03$ & $p=.04$ & $p<.01$ & $p<.01$ \\
\hline
\end{tabular}

Negotiation Experiences. We conducted a 2 (role: Boss vs. Candidate) within-pair x 2 (handshake: present vs. absent) between-pair ANOVA on each of the seven survey items about negotiators' experiences. Most relevant for our hypothesis, pairs who shook hands reported engaging in marginally more cooperative strategies than those who did not shake, $F(1,58)=3.58$, $p=.06, \eta_{p}{ }^{2}=0.06$, but just directionally reported being more open about their interests, $F(1,58)$ $=1.29, p=.26$ (see Figure 2 ). Pairs also reported having a significantly more positive impression of their partner if they shook hands, $F(1,58)=6.44, p=.01, \eta_{p}{ }^{2}=0.10$. No other items from the survey differed by experimental condition, $F_{S}(1,58)<1.92$. Bosses felt more comfortable at the 
start of the negotiation, enjoyed the negotiation more, and reported being more open about their interests, $F s(1,58)>4.28, p s<.04, \eta_{p}^{2}>0.07$. Only one role by experimental condition interaction emerged, $F(1,58)=4.62, p=.04, \eta_{p}{ }^{2}=0.07$, such that bosses directionally enjoyed the negotiation less when they shook hands (handshake vs. no handshake: $M=4.94, S D=1.69$ vs. $M=5.52, S D=1.18), t(58)=-1.53, p=.13$, whereas candidates directionally enjoyed the negotiation more when they shook hands (handshake vs. no handshake: $M=4.77, S D=1.09$ vs. $M=4.28, S D=1.33), \mathrm{t}(58)=1.59, p=.12$.

Mediation. As predicted, how openly pairs discussed their preferences on video fully mediated the effect of handshake on joint point outcomes, eliminating the effect of the handshake (from $\beta=2.20, p=.01$, to $\beta=0.48, p=.55$ ) when included in the model. A 5000sample bootstrap test estimated a significant indirect effect of 1.73 ( $\mathrm{SE}=0.56,95 \%$ biasedcorrected CI [.81, 2.98]) (MacKinnon, Fairchild, \& Fritz, 2007). Other behavioral variables that differed by condition (e.g., coded behaviors like posture or reported feelings like impression of partner) were not significant mediators. Likewise self-reported openness did not mediate the effect of handshake on point outcomes. ${ }^{4}$

\section{Discussion}

These results suggest that shaking hands induces greater openness about negotiators' preferences on contentious issues and improves joint outcomes. While shaking hands caused several additional positive changes in negotiators' behaviors consistent with cooperative motives, only openness played a critical role in producing better outcomes, as previous research on integrative negations would suggest (Weingart et al., 1996). Further, shaking hands predicted

\footnotetext{
${ }^{4}$ In this mediation model, shaking hands was directionally positively related to self-reported openness, $Д$ $=0.75, p=.26$, and self-reported openness was directionally positively related to joint outcomes, $Д=$ $0.16, p=.34$. Including self-reported openness in the model did not change the effect of handshake on joint outcomes.
} 
how openly participants actually behaved in the negotiation $(\beta=1.26, p<.01)$ more strongly than it predicted their self-reported openness $(\beta=0.75, p=.26)$.

The video coding of open behavior only weakly and non-significantly correlated with self-reported openness, $r=0.15, p=.27$. We note that our self-report measure of openness may not closely reflect actual behaviors of openness for at least two reasons. First, participants likely considered how openly they shared information about all three issues of the case when rating their own openness. However, because both parties wanted the same location (Chicago) - and in fact all pairs optimally selected this location —we disregarded behavior regarding the issue of location in our video coding. If both parties believed they were open about their preference for Chicago, this would be reflected in their self-report score but not in our behavioral code. Second, self-report variables are unlikely to perfectly predict real behavior due to social desirability concerns (e.g., Arnold \& Feldman, 1981); for instance, participants may have been inclined to report being more open than they actually were in the negotiation.

\section{Study 4: Distributive Negotiations}

In Study 4 we examine the effect of shaking hands on a different—and often more antagonistic - type of negotiation: a single-issue distributive negotiation. We predicted that cooperative motives would lead to a smaller point discrepancy within the zone of possible agreement (ZOPA), such that outcomes would be more equitable. Distributive negotiations are not affected by openness because each side's preferences are known to be in opposition; instead, many distributive negotiations involve asymmetric information, which negotiators can choose to disclose, hide — or lie about. We focus in particular on lies that distort the counterpart's perception of the ZOPA. We predicted that handshakes would reduce the number of lies told, 
which would reduce point discrepancy between negotiators. We explore these predictions with two classes of executives completing the same distributive negotiation for a negotiation class.

\section{Method}

Participants. One hundred seventy executives (133 males) who attended a negotiation course in the Executive Education Program at a top business school in the Northeastern United States completed a distributive negotiation.

Procedure. Participants negotiated a sale of real estate property. We randomly assigned participants to the role of "Seller" or "Buyer" in the negotiation. We instructed half of the pairs to shake hands before starting negotiations using similar instructions as in Study 3: "It is common for negotiators to shake hands prior to engaging in discussions at the bargaining table. Please shake your counterpart's hand prior to starting the negotiation." The other half did not receive any further instructions: "Please start the negotiation." After the negotiation, the Buyers completed a survey.

Materials. In the Hamilton Real Estate negotiation (Malhotra, 2010), a Seller offers a property for sale to a Buyer. The ZOPA ranges from $\$ 41.8$ million to $\$ 60$ million (i.e., from the Seller's reservation value to the Buyer's reservation value). This negotiation contains a key information asymmetry, with important consequences for the ZOPA. The Buyer knows that zoning laws will soon change, allowing him to develop the land as commercial (rather than residential) property, making it considerably more valuable; the Seller believes that zoning laws restricting development to residential property are unlikely to change. In short, the Buyer benefits from the Seller not knowing this information — such that lying about this information is tempting. The only issue the executives were asked to agree upon was the price for the property, making the negotiation a one-issue, zero-sum negotiation. 
Because Buyers (not Sellers) have the additional information that makes it tempting for them to lie and thus obtain a larger share of the ZOPA, we only surveyed the Buyers. Buyers first reported whether they had reached an agreement in the negotiation and, if so, the price at which they agreed to purchase the property from the Seller. In addition, they answered two questions assessing the extent to which they were intentionally misleading during the negotiation $(1=I$ was truthful; 7 = I was intentionally misleading): When discussing the issues of this negotiation with the Seller, in general, how intentionally misleading were you (e.g., lying about what was important to you or about information you had that you did not want to disclose)?; When discussing how you intended to use the property if you acquired it from the Seller, how intentionally misleading were you? We averaged these two items into a composite measure of lying $(\alpha=.71)$.

\section{Results}

We first computed the Buyer's profit based on the $\$ 18.2$ million ZOPA range from $\$ 41.8$ to $\$ 60$ million. The percentage of the overall ZOPA that the Buyer captured was our main dependent variable. For instance, if a dyad reached a final agreement of $\$ 45 \mathrm{M}$, the Buyer's profit would be $\$ 15 \mathrm{M}(\$ 60 \mathrm{M}-\$ 45 \mathrm{M})$, or $82 \%$ of the ZOPA captured $(\$ 15 \mathrm{M} / \$ 18.2 \mathrm{M})$. As predicted, when pairs shook hands, the percentage of the ZOPA captured by Buyers was closer to the equal split (i.e., 50\%) than when they did not shake hands (handshake vs. no handshake: $M=56.6 \%$, $S D=16.5 \%$ vs. $M=78.4 \%, S D=25.3 \%), t(83)=4.73, p<.01, d=1.04$.

In addition, Buyers who shook hands reported being less misleading than Buyers who did not (handshake vs. no handshake: $M=3.29, S D=1.53$ vs. $M=4.19, S D=1.37), t(83)=-2.85, p$ $=.01, d=-0.63$. The effect of shaking hands on the percentage of the ZOPA captured was reduced (from $\beta=-.46, p<.01$ to $\beta=-.41, p<.01$ ) when self-reported lying was included in the 
equation, and lying marginally predicted how much value they captured in the negotiation $(\beta$ $=.17, p=.09$ ). A bootstrap analysis showed that the $95 \%$ bias-corrected confidence interval excluded zero [0.61, 4.01], suggesting a significant indirect effect.

\section{Discussion}

In contrast to the effect of a handshake in an integrative negotiation, which increased joint outcomes and open priority exchange, a handshake in a distributive negotiation instead made outcomes more equitable and reduced lying behavior. Executives who shook hands before negotiating were less likely to lie to their counterparts and divided the available "pie" more evenly. Lying behavior partially, but not fully, mediated the relationship between shaking hands and point outcomes. We note that we could only collect self-reported lying in this study, which may not perfectly reflect actual lying behavior in the negotiations. A more objective measure of lying from videotapes of the negotiations (which we were unable to obtain for the current study) may have revealed a stronger effect of lies on point outcomes.

\section{General Discussion}

Children in conflict are often told by parents to "shake hands and make up," suggesting a belief in the cooperation-inducing properties of this simple gesture. Indeed, we show that adults also believe that handshakes signal cooperation — and further feel comfortable doing them in the adversarial context of a negotiation, making handshakes particularly relevant for negotiation outcomes. In both integrative and distributive negotiations, using executives, MBA students, and undergraduates, we show that shaking hands increases cooperative behavior, decreases antagonistic behavior, and produces systematically different negotiation outcomes. In integrative negotiations, shaking hands increased parties' willingness to openly discuss their priorities and make favorable exchanges on trade-off issues, leading to improved joint outcomes. The effect of 
handshakes on outcomes was fully mediated by open priority exchange. In a distributive negotiation with asymmetric information, shaking hands reduced lying and resulted in more equitable agreements. Decreased lying partially mediated the relationship between handshakes and percentage of ZOPA obtained. Taken together, these results suggest that the simple act of shaking hands is a powerful gesture that alters negotiation outcomes.

\section{Theoretical Implications}

Our work contributes to the literature in several ways. First, our data inform research on social motives. Prior research has found that individuals behave cooperatively in negotiations (and social dilemmas more generally) when they have cooperative goals and expect their counterpart to have cooperative goals too (e.g., Steinel \& DeDreu, 2004). Our results build on these findings by showing that people shake hands before negotiations as a signal of their willingness to cooperate. Based on our results, we can conclude that compared to negotiators who do not shake hands, those who do so are more open in the way they share information and are less likely to lie.

Second, our work contributes to research on the importance of building rapport in negotiation and conflicts more generally (Drolet \& Morris, 1999; Maddux, Mullen, \& Galinsky, 2008; Moore, Kurtzberg, Thompson, \& Morris, 1999). For instance, Drolet and Morris (1999) found that rapport enables coordination on solutions to mixed-motive conflicts and leads to integrative outcomes. Maddux and colleagues (2008) found that mimicking the mannerism of one's opponent in negotiation increases trust and value creation. Here, we demonstrated that handshaking may be a particularly easy intervention to build rapport and encourage trust in negotiations. The benefits of handshaking can be accrued not only in integrative negotiations but also in distributive ones. 
Our findings also extend prior research on the role of pre-play contact between parties in social dilemmas. This work has found that, through communication, parties can develop a shared identity that, in turn, encourages cooperation (e.g., Kerr, Garst, Lewandowski, \& Harris, 1997; Swaab, Lount, \& Brett, 2014). Here, we identified another route to the emotional aspect of communication: simply shaking hands before negotiations can increase cooperation at the bargaining table.

Finally, our work also contributes to research on rituals. Handshakes are just one of the many types of small acts that shape social interactions; indeed, many types of social interactions are guided by similar "everyday" rituals (e.g., Durkheim, 1912; Goffman, 1967). Mirroring our results for the positive effects of handshakes, successful social rituals increase positive emotions, and can induce prosociality in groups (Collins, 2004; Xygalatas et al., 2013). Whereas this previous research suggests that rituals can increase harmony in existing groups, our results suggest that such rituals can have positive effects even in more antagonistic settings: negotiations between parties in conflict. Our results also contribute to an emerging literature on the positive impact of rituals on individuals in many domains, from alleviating grief (Norton \& Gino, 2014) to improving consumption experiences (Vohs, Wang, Gino, \& Norton, 2013) to reducing anxiety (Brooks et al., 2014). We show that a simple everyday ritual such as a handshake can create positive outcomes not just for individuals, but for dyads.

\section{Directions for Future Work}

Our results raise several questions for future research. Although we argue that handshakes are particularly relevant for negotiations because of people's willingness to engage in them at the start of the negotiation, it seems possible that other nonverbal gestures could also incite cooperation even if people do not prefer to engage in them. Research points to the 
powerful role of physical touch in changing emotion and behavior (e.g., Levav \& Argo, 2010; Stephen \& Zweigenhaft, 1986). In a variety of domains, touch communicates compassion (Hertenstein, Keltner, App, Bulleit, \& Jaskolka, 2006), increases trust (Kurzban, 2001), incites cooperation (Kraus, Huang, \& Keltner, 2010), and is even used among primates to communicate and affiliate with each other (De Waal, 1989). Other positive greeting gestures — such as a wave or smile — could also evoke cooperative behavior. Indeed, smiling increases cooperative behavior in economic games (Krumhuber et al., 2007; Scharlemann, Eckel, Kacelnik, \& Wilson, 2001). Could other types of minimal touch, such as a brief pat on the arm, or other positive greetings, such as a smile, affect negotiation outcomes?

Relatedly, what are the aspects of a handshake that are most necessary to produce prosociality? Does the quality of handshakes moderate their effectiveness? Intuitively and empirically, limp handshakes may be aversive (Stewart et al., 2008). Given the critical role of synchrony in cooperative rituals (Wiltermuth \& Heath, 2009), it is also possible that failed handshakes (e.g., when one person releases before the other) may have negative effects. This negative impact of failed synchrony may have particular resonance in cross-cultural settings. Bowing is common in Japan, shaking hands in America. If cooperative motives are deduced from the goodwill associated with greeting rituals, returning a proffered hand with a bow would still have positive outcomes; if not, then a handshake returned with a bow may be worse than no greeting ritual at all. Research by Pillutla and Chen (1999) found that individuals' behavior in a social dilemma situation differed depending on whether they learned that others' behavior was consistent or inconsistent with expectations. Similarly, if negotiators expect their counterparty to shake hands and the counterparty does not, the lack of handshaking may be particularly costly to reaching a deal. As Iranian President Rouhani's refusal to shake American President Obama’s 
hand may suggest, the act of refusing to shake hands could incite antagonism as strongly as the act of shaking hands incites cooperation.

Future research could also further examine the psychological consequences of shaking hands prior to negotiations. In addition to signaling cooperation, shaking hands may influence positive affect, which has been shown to increase integrative agreements (Carnevale \& Isen, 1986). Thus, the effects of handshakes on deal making may be both cognitive and emotional.

\section{Conclusion}

Humans use subtle sources of information — like nonverbal behavior- to determine whether to act cooperatively or antagonistically when they negotiate. One such nonverbal behavior is to shake hands before negotiations. People feel comfortable shaking hands at the start of a negotiation and believe handshakes convey a willingness to cooperate. In this paper, we proposed and found that handshakes increase cooperative behaviors, affecting outcomes for both integrative and distributive negotiations. 


\section{References}

Ambady, N., \& Rosenthal, R. (1992). Thin slices of expressive behavior as predictors of interpersonal consequences: A meta-analysis. Psychological Bulletin, 111, 256-274.

Amabady, N., \& Rosenthal, R. (1993). Half a minute: Predicting teacher evaluations from thin slices of nonverbal behavior and physical attractiveness. Journal of Personality and Social Psychology, 64, 431-441.

Ames, D. L., Fiske, S. T., \& Todorov, A. (2011). Impression formation: A focus on others' intents. In J. Cacioppo (Ed.), The Oxford handbook of social neuroscience (pp. 419-433). New York: Oxford University Press.

Argyle, M. (1988). Bodily communication. New York: Methuen \& Co.

Arnold, H. J., \& Feldman, D. C. (1981). Social desirability response bias in self-report choice situations. Academy of Management Journal, 24, 377-385.

Astrom, J. (1994). Introductory greeting behavior: A laboratory investigation of approaching and closing salutation phases. Perceptual and Motor Skills, 79, 863-897.

Brooks, A. W., Schroeder. J. R., Risen, J., Gino, F., Galinsky, A., Norton, M. I., \& Schweitzer, M. (2014). Don't stop believing: Coping with anxiety through rituals. Manuscript under review.

Burgoon, J. K. (1991). Relational message interpretations of touch, conversational distance, and posture. Journal of Nonverbal Behavior, 15, 233-259.

Burgoon, J. K., Buller, D. B., \& Woodall, W. G. (1989). Nonverbal communication: The unspoken dialogue. New York: Harper \& Row.

Burgoon, J. K., Buller, D. B., Hale, J. L., \& deTurck, M. A. (1984). Relational messages associated with nonverbal behaviors. Human Communication Research, 10, 351-378. 
Carnevale, P. J. D., \& Isen, A. M. (1986). The influence of positive affect and visual access on the discovery of integrative solutions in bilateral negotiation. Organizational Behavior and Human Decision Processes, 37, 1-13.

Chaplin, W. F., Phillips, J. B., Brown, J. D., Clanton, N. R., \& Stein, J. L. (2000). Handshaking, gender, personality and first impressions. Journal of Personality and Social Psychology, $79,110-117$.

Collins, R. (2004). Interaction Ritual Chains. Princeton: Princeton University Press.

De Gelder, B., Van den Stock, J., Meeren, H. K. M., Sinke, C. B. A., Kret, M. E., \& Tamietto, M. (2010). Standing up for the body. Recent progress in uncovering the networks involved in processing bodies and bodily expressions. Neuroscience and Biobehavioral Reviews, 34, $513-527$.

De Dreu, C. K. W., Weingart, L. R., \& Kwon, S. (2000). Influence of social motives on integrative negotiation: A meta-analytic review and test of two theories. Journal of Personality and Social Psychology, 78, 889-905.

De Waal, F. (1989) Peacemaking among primates. Cambridge, MA: Harvard University Press.

DePaulo, B. M. (1992). Nonverbal behavior and self-presentation. Psychological Bulletin, 111, 203-243.

Deutsch, M. (1949). A theory of cooperation and competition. Human Relations, 2, 199-231.

Drolet, A. L., \& Morris, M. W. (1999). Rapport in conflict resolution: Accounting for how faceto-face contact fosters mutual cooperation in mixed-motive conflicts. Journal of Experimental Social Psychology, 36, 26-50. 
Dulcos, S., Sung, K., Argo, J. L., Flor-Henry, S., \& Dolcos, F. (2012). Power of a handshake: Neural correlates of evaluative judgments in observed social interactions. Journal of Cognitive Neuroscience, 24, 2292-2305.

Durkheim, E. (1912/1964). The Elementary Forms of Religious Life. New York: Free Press.

Fehr, E., \& Fischbacher, U. (2003). The nature of human altruism. Nature, 425, 785-791.

Fishbach, A. (2013). Job Search negotiation case.

Fisher, R., \& Ury, W. (1981). Getting to yes: Negotiating agreement without giving in. Boston, MA: Houghton Mifflin.

Funder, D. C., \& Colvin, C. R. (1988). Friends and strangers: Acquaintanceship, agreement, and the accuracy of personality judgment. Journal of Personality and Social Psychology, 55, 149-158.

Gallace, A., \& Spence, C. (2010). The science of interpersonal touch: An overview. Neuroscience and Biobehavioral Reviews, 34, 246-259.

Giebels, E., De Dreu, C. K. W., \& Van de Vliert, E. (2000). Interdependence in negotiation: Effects of social motive and exit options on distributive and integrative negotiation. European Journal of Social Psychology, 30, 255-272.

Goffman, E. (1967). Interaction Ritual. New York: Doubleday.

Hall, J. A., \& Schmid-Mast, M. (2007). Sources of accuracy in the empathic accuracy paradigm. Emotion, 7, 438-446.

Harlow, H. F. (1958). The nature of love. American Psychologist, 13, 673-685.

Henrich, J. (2012). Hunter-gatherer cooperation. Nature, 481, 449-450.

Hertenstein, M. J., Keltner, D., App, B., Bulleit, B. A., \& Jaskolka, A. R. (2006). Touch communicates distinct emotions. Emotion, 6, 528-533. 
Kelley, H. H., \& Thibaut, J. W. (1978). Interpersonal relations: A theory of interdependence. New York/Chichester/Brisbane/Toronto: Wiley \& Sons.

Kerr, N. L., Garst, J., Lewandowski, D. A., \& Harris, S. E. (1997). That still, small voice: Commitment to cooperate as an internalized versus social norm. Personality and Social Psychology Bulletin, 23, 1300-1311.

Kraus, M. W., Huang, C., \& Keltner, D. (2010). Tactile communication, cooperation, and performance: An ethological study of the NBA, Emotion, 10, 745-749.

Krumhuber, E., Manstead, A. S. R., Cosker, D., Marshall, D., Rosin, P. L., \& Kappas, A. (2007). Facial dynamics as indicators of trustworthiness and cooperative behavior. Emotion, 7, $730-735$.

Kurzban, R. (2001). The social psychophysics of cooperation: Nonverbal communication in a public goods game. Journal of Nonverbal Behavior, 25, 241-259.

Landler, M. (2013, September 25). Obama and Iranian leader miss each other, diplomatically. The New York Times, p. A9.

Levav, J., \& Argo, J. J. (2010). Physical contact and financial risk taking. Psychological Science, $21,804-810$

MacKinnon, D. P., Fairchild, A. J., \& Fritz, M. S. (2007). Mediation analysis. Annual Review of Psychology, 58, 593-614.

Maddux, W. W., Mullen, E., \& Galinsky, A. (2008). Chameleons bake bigger pies and take bigger pieces: Strategic behavioral mimicry facilitates negotiation outcomes. Journal of Experimental Social Psychology, 44(2), 461-468.

Malhotra, D. (2010). Hamilton Real Estate negotiation case. 
Moore, D. A., Kurtzberg, T. R., Thompson, L. L., \& Morris, M. W. (1999). Long and short routes to success in electronically-mediated negotiations: Group affiliations and good vibrations. Organizational Behavior and Human Decision Processes, 77, 22-43.

Murnighan, J. K., Babcock, L., Thompson, L. L., \& Pillutla, M. (1999). The information dilemma in negotiations: Effects of experience, incentives, and integrative potential. International Journal of Conflict Management, 10, 313-339.

Nadler, J., Thompson, L., \& Morris, M. (1998). New Car negotiation case.

Neale, M. A. (2006). New Recruit negotiation case.

Neale, M. A., \& Northcraft, G. B. (1991). Behavioral negotiation theory: A framework for conceptualizing dyadic bargaining. Research in Organizational Behavior, 13, 147-190.

Norton, M. I., \& Gino, F. (2014). Rituals alleviate grieving for loved ones, lovers, and lotteries. Journal of Experimental Psychology: General.

Pillutla, M. M., \& Chen, X. P. (1999). Social norms and cooperation in social dilemmas: The effects of context and feedback. Organizational Behavior and Human Decision Processes, 78, 81-103.

Pruitt, D. G. (1981). Negotiation Behavior. New York: Academic.

Pruitt, D. G., \& Lewis, S. A. (1975). Development of integrative solutions in bilateral negotiation. Journal of Personality and Social Psychology, 31, 621-633.

Pruitt, D. G., \& Rubin, J. Z. (1986). Social conflict: Escalation, stalemate, and settlement. New York: Random House.

Raiffa, H. (1982). The art and science of negotiation. Cambridge, MA: Harvard University Press. Scharlemann, J. P. W., Eckel, C. C., Kacelnik, A., \& Wilson, R. K. (2001). The value of a smile: Game theory with a human face. Journal of Economic Psychology, 22, 617-640. 
Steinel, W., \& DeDreu, C. K. W. (2004). Social motives and strategic misrepresentation in social decision making. Journal of Personality and Social Psychology, 86(3), 419-434.

Stephen, R., \& Zweigenhaft, R. L. (1986). The effect on tipping of a waitress touching male and female customers. Journal of Social Psychology, 126, 141-142.

Stewart, G. L., Dustin, S. L., Barrick, M. R., \& Darnold, T. C. (2008). Exploring the handshake in employment interviews. Journal of Applied Psychology, 93, 1139-1146.

Swaab, R. I., Lount, R., \& Brett, J. M. (2014). Pre-meeting to promote success: Facilitating intergroup cooperation and trust through the use of meetings prior to negotiations. Manuscript in preparation.

Thompson, L. L., Mannix, E. A., \& Bazerman, M. H. (1988). Negotiation: Effects of decision rule, agenda and aspiration. Journal of Personality and Social Psychology, 54, 86-95.

Thompson, L., \& Hastie, R. (1990). Social perception in negotiation. Organizational Behavior and Human Decision Processes, 47, 98-123.

Todorov, A., Mandisodza, A. N., Goren, A., \& Hall, C. C. (2005). Inferences of competence from faces predict election outcomes. Science, 308, 1623-1626.

Van Lange, P. A. M. (1999). The pursuit of joint outcomes and equality in outcomes: An integrative model of social value orientations. Journal of Personality and Social Psychology, 77, 337-349.

Vohs, K. D., Wang, Y., Gino, F., \& Norton, M. I. (2013). Rituals enhance consumption. Psychological Science, 24, 1714-1721.

Weingart, L. R., Bennett, R. J., \& Brett, J. M. (1993). The impact of consideration of issues and motivational orientation on group negotiation process and outcome. Journal of Applied Psychology, 78, 504-517. 
Weingart, L. R., Hyder, E. B., \& Prietula, M. J. (1996). Knowledge matters: The effect of tactical descriptions on negotiation behavior and outcome. Journal of Personality and Social Psychology, 70, 1205-1217.

Willis, J., \& Todorov, A. (2006). First impressions: Making up your mind after a 100-ms exposure to a face. Psychological Science, 17, 592-598.

Wiltermuth, S. S., \& Heath, C. (2009). Synchrony and cooperation. Psychological Science, 20, 1-5.

Xygalatas, D., Mitkidis, P., Fischer, R., Reddish, P., Skewes, J., Geertz, A. W., Roepstorff, A., \& Bulbulia, J. (2013). Extreme rituals promote prosociality. Psychological Science, 24, $1602-1605$. 
Figure 1. The effect of shaking hands or not and participants' roles on points achieved in an integrative negotiation in Study 3.

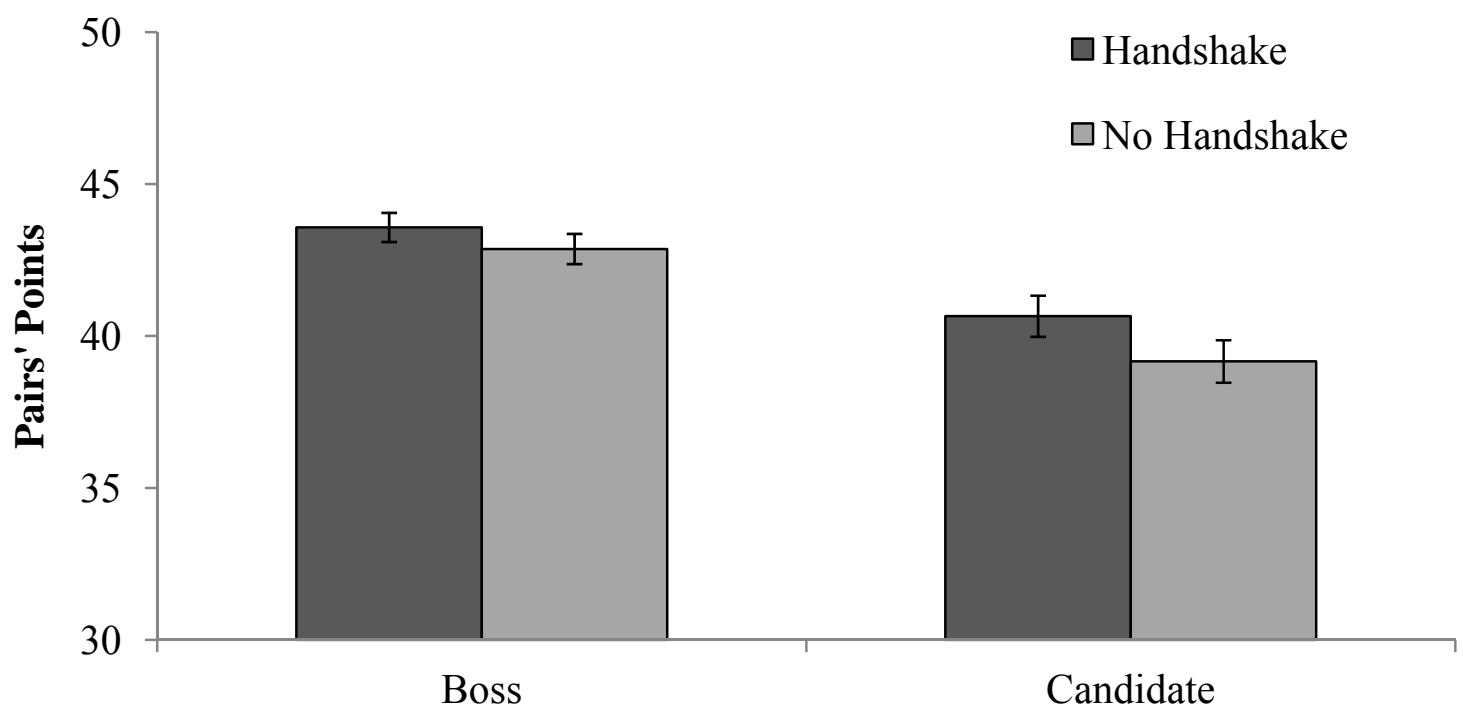


Figure 2. Participants' reported experiences in an integrative negotiation as a function of whether or not they shook hands in Study 3.

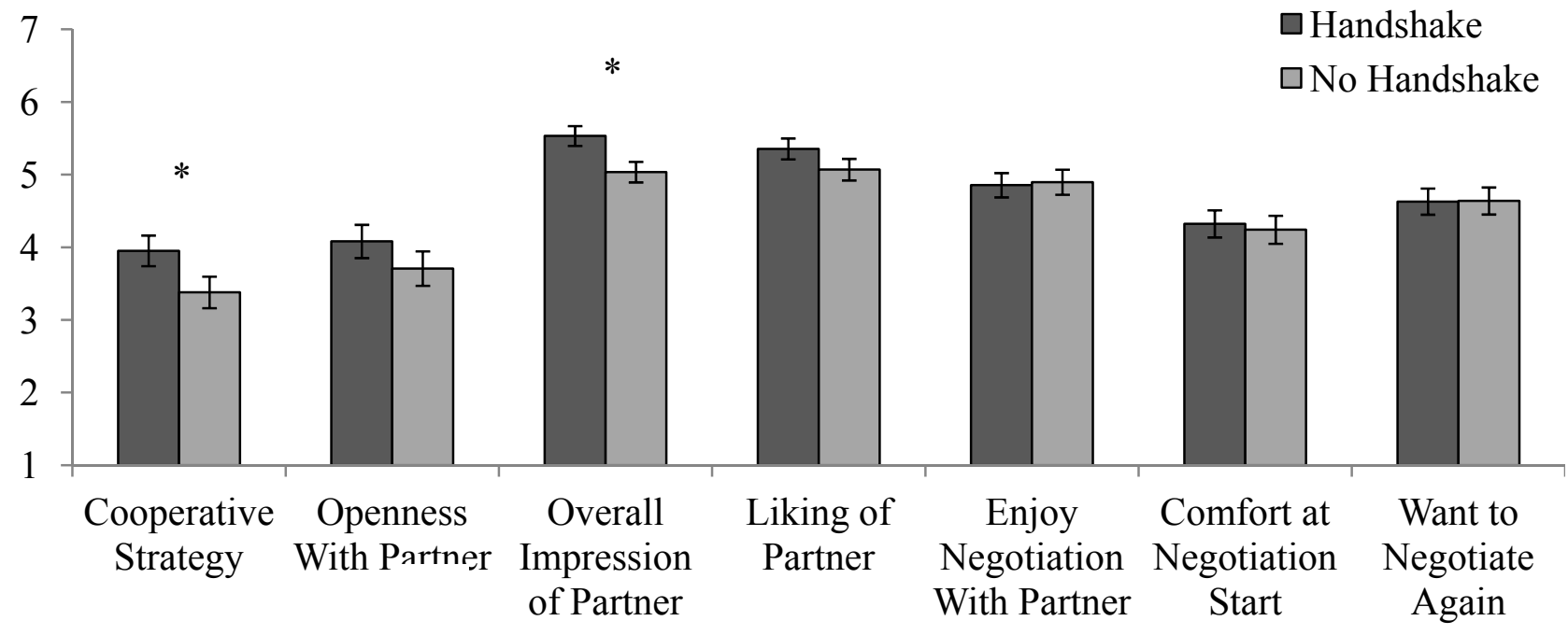

Note: $* \mathrm{p}<.05$ 